\title{
The features of metal powders consolidation by layer-by-layer electric discharge sintering
}

\author{
I. A. Elkin ${ }^{1, \dagger}$, V. A. Volkov ${ }^{1}$, K. S. Stolbov ${ }^{2}$, D. A. Kolodkin, A. A. Chulkina ${ }^{1}$, A. N. Bel'tyukov ${ }^{1}$ \\ †ivan.a.elkin@gmail.com
}

${ }^{1}$ Udmurt Federal Research Center, Ural Branch of RAS, 34 T. Baramzinoy str., Izhevsk, 426067, Russia

${ }^{2}$ Udmurt State University, 1/1 Universitetskaya str., Izhevsk, 426034, Russia

${ }^{3}$ M.N. Mikheev Institute of Metal Physics, Ural Branch of RAS, 18 S. Kovalevskoy str., Yekaterinburg, 620137, Russia

\begin{abstract}
Additive technologies (3D printing), i.e. layer-by-layer production of bulk materials from powder precursors, are very promising in the modern industry. These technologies make it possible to obtain products with complex geometric shapes and materials with a unique variety of properties. The range of products which can be obtained by $3 \mathrm{D}$ printing is extremely wide, therefore the search for new methods and techniques of $3 \mathrm{D}$ printing is of great current interest. This paper suggests a method of obtaining bulk materials of a complex shape from electroconductive powders based on the technology of spot electric discharge sintering. This method is a layer-by-layer consolidation of powders, where each layer is formed as a result of successive spot sintering of small amounts of powder compressed between the electrode and the substrate, or between the electrode and the previously sintered layer. It is shown that the method developed makes it possible to obtain bulk samples from powders with various chemical compositions $(\mathrm{Cu}, \mathrm{Ti}$, mechanically synthesized tin bronze), particles of various shapes (dendritic, dumbbell-, and stone-like), and of various structural-phase states. The structural-phase states and porosity of the obtained bulk materials were studied by the X-ray diffraction and electron microscopy. The powders sintered by the method are mostly affected by the heat release along the boundaries of the grains of the powder which, in its turn, depends on the electrical resistivity of the material and the structural-phase transformations in the process of consolidation. The porosity of the sintered samples mainly depends on the type of the powder used and decreases with the decrease in the size of the grains of the powder.
\end{abstract}

Keywords: additive technologies, electric-discharge sintering, metal powders, porous structure.

УДК: 673

\section{Особенности консолидации металлических порошков}

\section{в результате послойного электроимпульсного спекания}

\author{
Елькин И. А. ${ }^{1, \dagger}$, Волков В. А. ${ }^{1}$, Столбов К. С. ${ }^{2}$, Колодкин Д. А. ${ }^{3}$, Чулкина А. А. ${ }^{1}$, \\ Бельтюков А.Н. ${ }^{1}$ \\ ${ }^{1}$ Удмуртский федеральный исследовательский центр УрО РАН, ул. Т. Барамзиной 34, Ижевск, 426067, Россия \\ ${ }^{2}$ Удмуртский государственный университет, ул. Университетская 1/1, Ижевск, 426034, Россия \\ ${ }^{3}$ Институт физики металлов имени М.Н. Михеева УрО РАН, ул. С. Ковалевской 18, Екатеринбург, 620137, Россия
}

\begin{abstract}
Аддитивные технологии (3D печать, трехмерная печать) или технологии послойного получения объемных материалов из порошковых прекурсоров имеют огромные перспективы в современной промышленности. Благодаря таким технологиям удается получать изделия, обладающие сложной геометрической формой, а также материалы, обладающие уникальным комплексом свойств. Перечень изделий перспективных с точки зрения получения трехмерной печати чрезвычайно широк, поэтому идет постоянный поиск новых методов, приемов и технологий трехмерной печати. В настоящей работе предложен способ получения объемных материалов сложной формы из электропроводящих порошков, основанный на технологии точечного, послойного электроимпульсного спекания. Данный метод заключается в послойной консолидации порошков, причем каждый слой формируется в результате последовательного поточечного спекания небольших порций порошка, сжатых между электродом и подложкой, либо между электродом и предыдущим спеченным слоем. В работе, с помощью предложенного способа, получены объемные образцы из порошков, обладающих разным химическим составом $(\mathrm{Cu}, \mathrm{Ti}$, механосинтезированная оловянистая бронза), частицами различной формы (дендритная, гантелеобразная, камнеобразная), и различным структурно-фазовым состоянием. При помощи рентгеновской дифракции, электронной микроскопии исследованы структурно-фазовые состояния и пористость полученных объемных консолидированных материалов. Большое влияние на спекание по-
\end{abstract}


рошков используемым методом оказывает тепловыделение по границам порошинок, которое в свою очередь зависит от удельного электросопротивления материала и происходящих структурно-фазовых превращений в процессе спекания. Пористость спеченных образцов, главным образом, зависит от типа использованного порошка и уменьшается с уменьшением размера порошинок.

Ключевые слова: аддитивные технологии, электроимпульсное спекание, металлические порошки, пористая структура.

\section{1. Введение}

Аддитивные технологии (3D печать, трехмерная печать) имеют огромные перспективы в современной промышленности. Благодаря этим технологиям удается изготавливать изделия, обладающие сложной формой, а также получать материалы, обладающие уникальными комплексами свойств. Наиболее распространенными методами 3D печати с использованием металлических порошков в настоящее время являются: селективное лазерное сплавление [1], прямое лазерное наплавление [2], сплавление электронно-лучевой пушкой [3]. Несмотря на то, что эти методы широко используются, обеспечивая высокую точность формы изделия, они не лишены недостатков. К наиболее серьезным относится использование сложного и дорогостоящего оборудования, а также получение деталей без остаточной пористости c хорошей шероховатостью поверхности. Остаточная пористость и нестабильность расплава могут быть устранены за счет выбора оптимальных параметров процесса получения $[4,5]$, что накладывает ограничение на диапазон используемых материалов [6]. Чаще всего используются порошки нелегированных низко- и высокоуглеродистых сталей [7], порошки нержавеющих [8], быстрорежущих [9] и инструментальных сталей [10], а также порошки на основе сплавов титана [11].

Перечень изделий перспективных с точки зрения получения трехмерной печати чрезвычайно широк, поэтому идет постоянный поиск новых методов и приемов трехмерной печати. В некоторых случаях более эффективно использование простой и надежной аппаратуры, позволяющей получать, возможно, более грубые изделия, но с наименьшими затратами. Для этих целей может быть использован метод электроимпульсного спекания [12 - 16]. Этот метод широко применяется для получения высокопрочных, композитных нанокристаллических материалов, а также композиции металл - керамика [17]. В настоящей работе предложен метод, который можно назвать развитием электроимпульсного спекания. Метод заключается в нанесении слоя электропроводящего порошка на поверхность формируемой детали, сжатии порошка в точке между деталью и электродом и спекании в этой точке за счет пропускания электрического импульса. В результате прохождения электрического тока происходит разогрев, главным образом, контактов между порошинками и сваривание частиц порошка по их границам. Последовательное поточечное спекание приводит к образованию нового слоя. Поскольку данный метод 3-D печати находится в стадии разработки, то целью работы являлось исследование влияния режимов получения, материалов используемых порошков, их дисперсности и морфологии на качество формируемых материалов.

\section{2. Материалы и методики}

Получение образцов осуществлялось по схеме, представленной на Рис. 1. Сначала в зоне построения формировался слой порошка определенной толщины, который спекался в заданных границах. Для позиционирования электрода в плоскости $X-Y$ в границах обрабатываемого слоя, а также для изменения его высоты над обрабатываемой поверхностью использовался миниатюрный 3-х координатный фрезерный станок с автоматическим управлением. Для спекания образцов использовался импульсный источник переменного тока с амплитудой выходного напряжения 0.5 В и тока 10 А. Продолжительность импульса составляла 20 мс. Медный электрод имел диаметр 1 мм, шаг сканирования электродом изменялся от 0.3 до 0.7 мм. При получении образцов начало сканирования каждого последующего слоя смещалось относительно предыдущего на половину шага сканирования для увеличения плотности спекаемого материала. Насыпная толщина порошковых слоев составляла 0.25 мм, давление электрода на порошок - 3 МПа. В результате сжатия и спекания слоя его толщина уменьшалась до 0.1 мм.

Для апробации предложенной методики получения объемных образцов применялись порошки, приготовленные из разных металлических материалов, обладающие различным структурно-фазовым состоянием, различной формой и размером частиц. Использовались порошки меди ПМС-1, титана ПТМ-1, бронзы БрО20 (Cu-20 вес.\% Sn). Порошок бронзы состава $\mathrm{Cu}-20$ вес.\% Sn получали в результате механосплавления порошков меди и олова в шаровой планетарной мельнице Fritch Pulverisette-7 в течение 18 ч, в атмосфере аргона. Форма частиц порошка меди - дендритная, порошка титана - гантелеобразная, порошка бронзы - камневидная (Рис. 2). Размер частиц порошка меди по данным электронной микроскопии был равен 30-50 мкм, титана - от 3 до 25 мкм, бронзы - около 55 мкм. Использованные в работе материалы характеризовались различным удельным электросопротивлением, удельное электросопротивление массивных меди, бронзы и титана $17.5 \cdot 10^{-9}, 95-100 \cdot 10^{-9}$ и $600 \cdot 10^{-9}$ Ом $\cdot$ м, соответственно $[18,19]$. В зависимости от характеристик материала порошков слои, формируемые из них, имели различное электросопротивление. Спекание порошков проводилось в воздушной атмосфере.

Структурное состояние и фазовый состав образцов после механического сплавления и последующего спекания исследовали методами рентгеновской дифракции (MiniFlex 600, излучение Co-Ка) и электронной микроскопии (Quanta-200). Качественный и количественный рентгенофазовый анализ, определение размера областей когерентного рассеяния (ОКР) проводили при помощи 


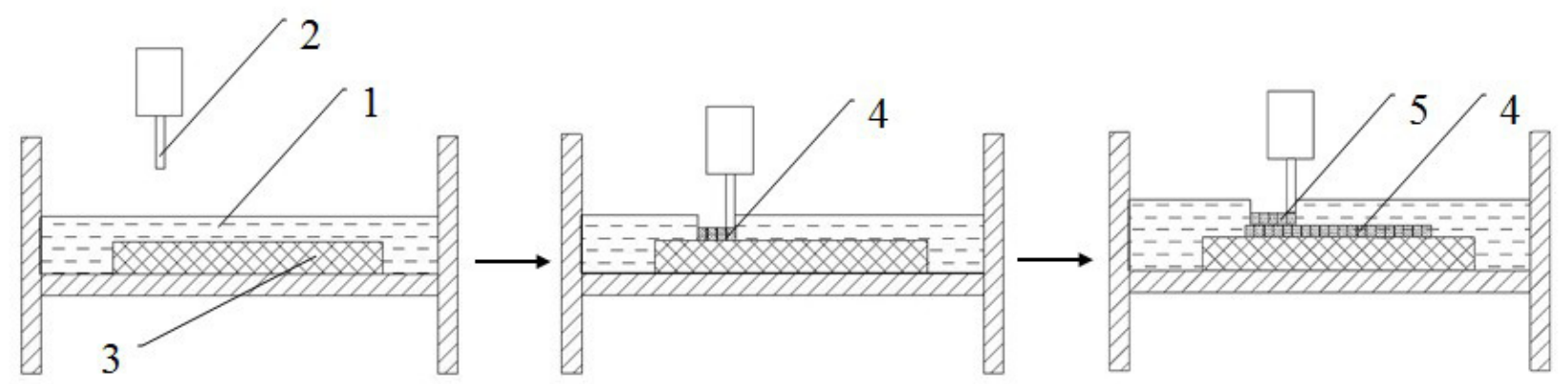

Рис. 1. Схема послойного, поточечного электроимпульсного спекания, где 1 - исходный порошок; 2 - электрод; 3 - электропроводящее основание; 4,5 - спеченные слои.

Fig. 1. The scheme of layer by layer, dot by dot electric-pulse sintering, where 1 is the initial powder; $2-$ electrode; $3-$ metal base; $4,5-$ sintered layers.

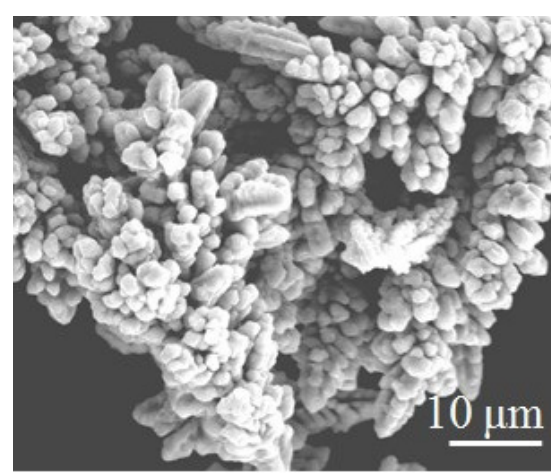

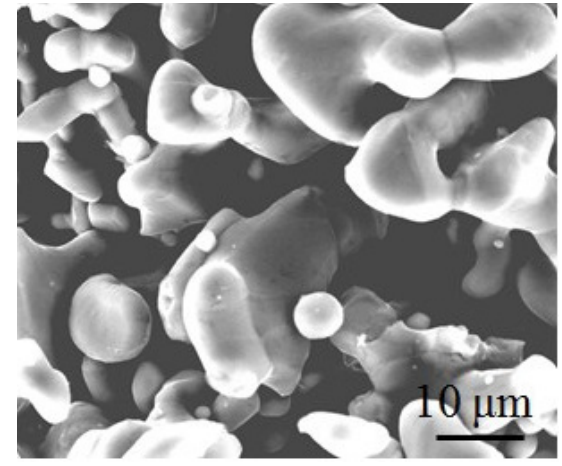

$\mathrm{b}$

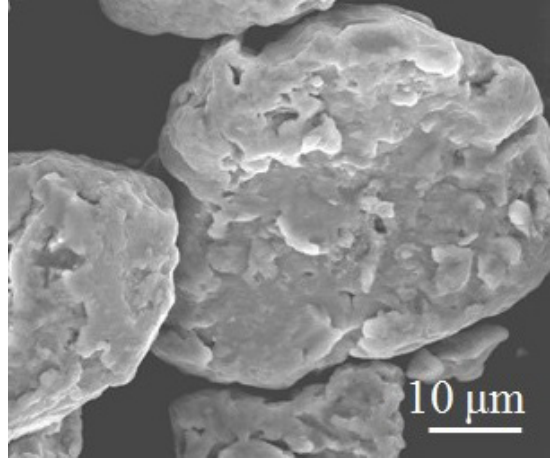

c

Рис. 2. Электронно-микроскопические изображения порошков Сu (a), Тi (b), МС бронзы (c).

Fig. 2. Electron microscopic images of the $\mathrm{Cu}$ (a), Ti (b), MS bronze (c) powders.

программы Match 3, определение пористости осуществлялось в результате анализа электронно-микроскопических изображений по измерению отношения площади темных участков к площади изображения.

\section{3. Результаты}

Описанным выше способом были получены объемные образцы в виде пластин различных размеров, толщиной 1 мм на основе порошка меди (Рис. 3a) и бронзы (Рис. 3c), а также толщиной 0.7 мм на основе порошка титана (Рис. 3b). Образец на основе титана состоял из 7 спеченных слоев, образцы из меди и бронзы из 10 слоев каждый. Не возникало принципиальных затруднений для получения образцов большей толщины. Из рисунка видно, что образцы не имеют признаков коробления и расслоения спеченных слоев.

На Рис. 4 приведены электронно-микроскопические изображения поперечных сечений образцов, полученных на основе порошка меди, титана и бронзы.

Из рисунка видно, что образцы имеют пористую структуру. На пористость полученных образцов существенным образом влияет тип использованного порошка. Из Рис. 4b видно, что наименьшим размером пор характеризуется образец на основе титана (размер пор 2 -6 мкм, пористость 9\%), а наибольшим - образец на основе бронзы (размер пор 33-95 мкм, пористость 24\%) (Рис. 4c). На изображении титанового образца в нижнем левом углу обнаруживается область с повышенной пори- стостью, которая может быть связана с выкрашиванием части образца в процессе приготовления шлифа, а также с неплотным прессованием исходного порошка. Образец на основе медного порошка имеет поры размером от 12 до 30 мкм и наибольшую пористость - 35\%. Судя по полученным данным, пористость образцов и размер пор увеличиваются с увеличением размера частиц порошков. Необходимо добавить, что в способах 3D печати с использованием лазера при полном расплавлении исходного порошка остаточная пористость может быть от 0 до 7\% в зависимости от типа используемого порошка [20]. Процесс электроимпульсного спекания позволяет получить компакт как с плотностью практически равной теоретической [21], так и с требуемой пористостью [22]. Можно отметить, что предлагаемый в работе способ также позволяет получать образцы с вариативной пористостью.

О степени нагрева материала при сваривании частиц порошка в некоторой степени можно судить по изменениям структуры. На Рис. 5 представлены рентгеновские дифрактограммы исходных порошков (верхние рисунки), а также образцов после спекания (нижние рисунки). Рентгеноструктурный анализ является хорошо известным способом анализа фазового состава и структуры материалов [23-24]. Изменения фазового состава приводят к изменению наборов и интенсивности дифракционных линий, а по их уширению можно судить о размерах ОКР и действующих микроискажениях.

Несмотря на малые размеры частиц исходных порошков они являются монофазными или гетерофаз- 


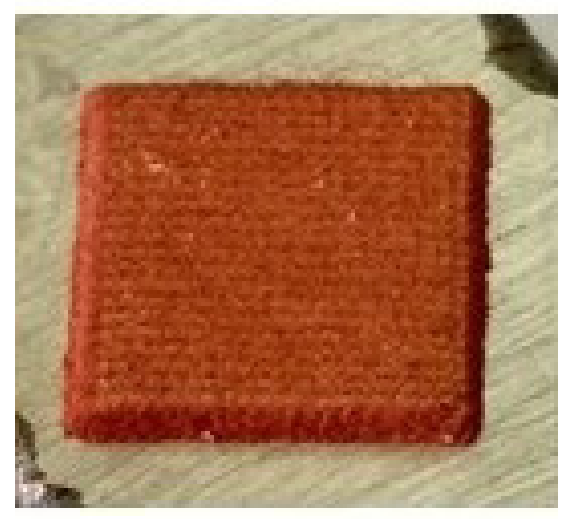

$2 \mathrm{~mm}$

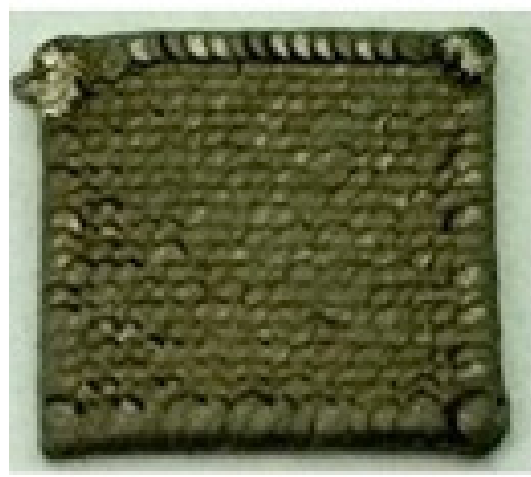

$2 \mathrm{~mm}$

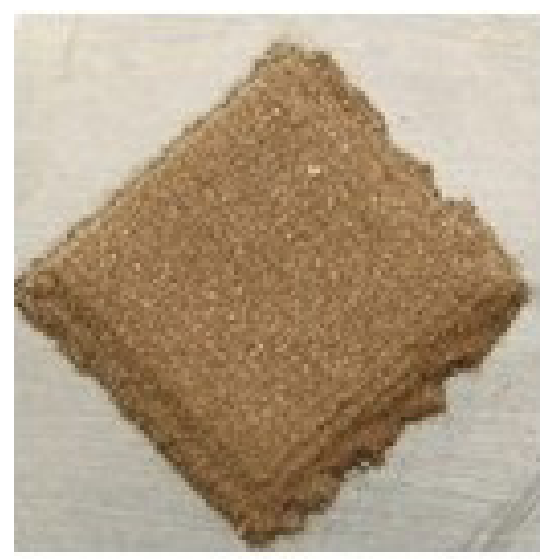

$2 \mathrm{~mm}$

a

b

Pис. 3. Изображения спеченных образцов на основе меди (a), титана (b), МС бронзы (c).

Fig. 3. Images of sintered samples based on copper (a), titanium (b), MS bronze (c).

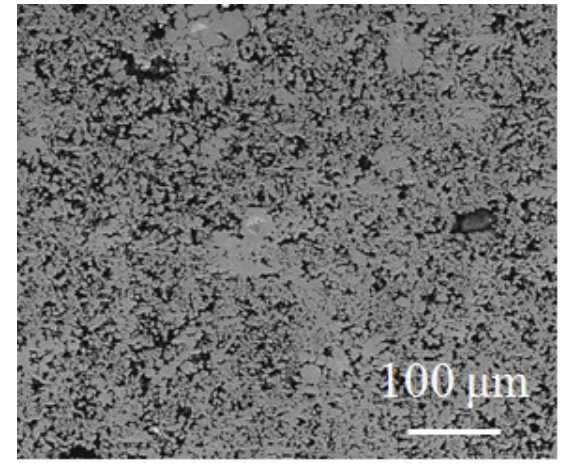

a

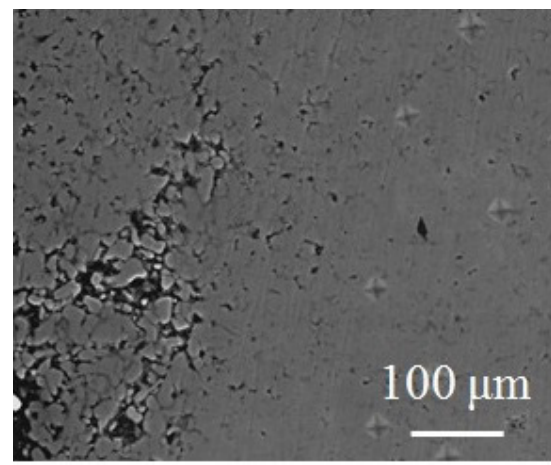

b

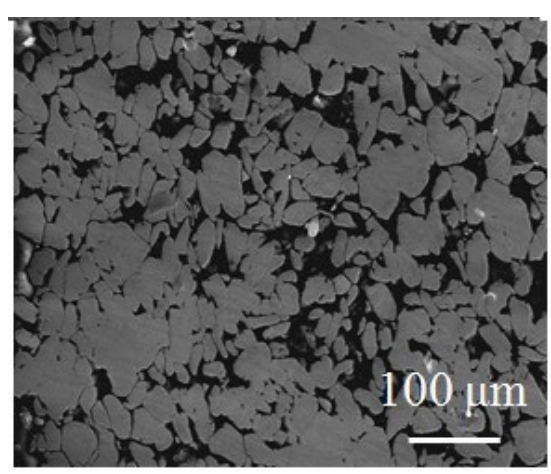

c

Рис. 4. Электронно-микроскопические изображения пористой структуры образцов, спеченных на основе порошка меди (а), титана (b), МС бронзы (c).

Fig. 4. Electron microscopic images of the porous structure of sintered samples based on the copper powder (a), titanium (b), MS bronze (c).

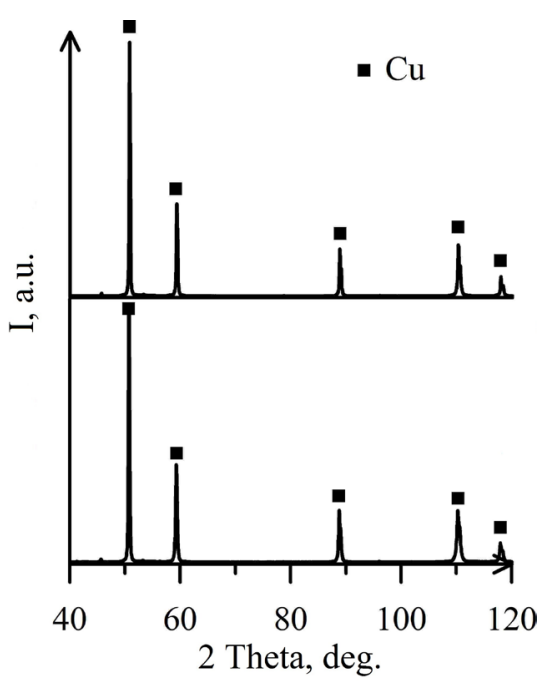

a

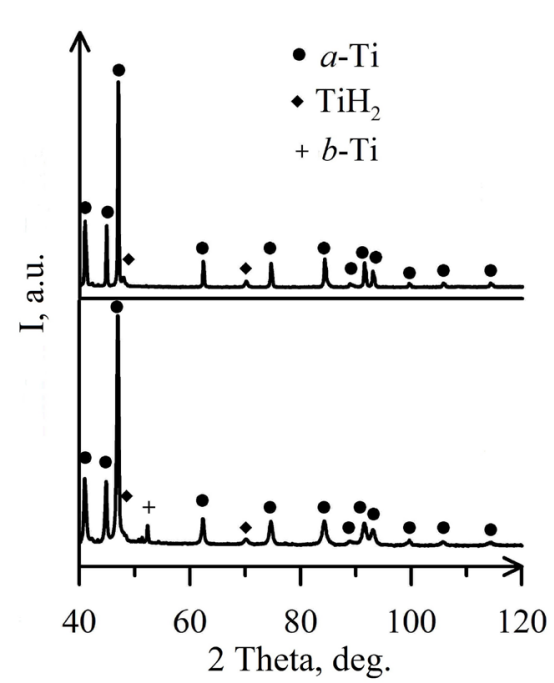

b

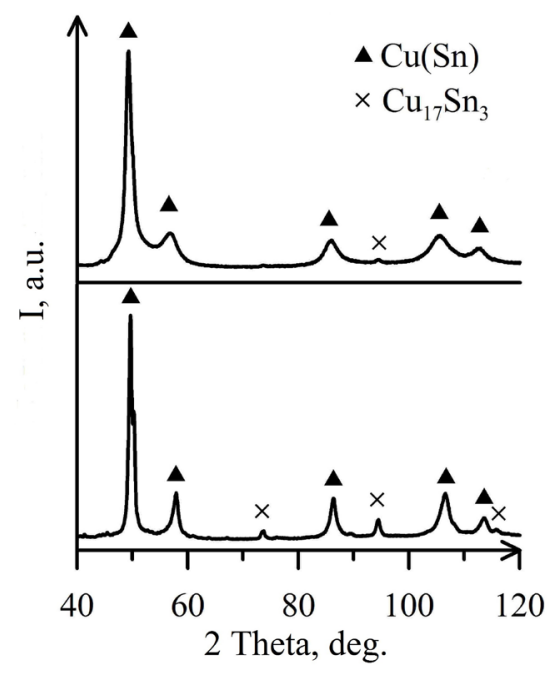

C

Рис. 5. Рентгенограммы исходных порошков $\mathrm{Cu}(\mathrm{a}), \mathrm{Ti}(\mathrm{b}), \mathrm{MC}$ бронзы (c) (верхние рисунки) и образцов после спекания данных порошков (нижние рисунки).

Fig. 5. X-ray diffraction of the initial $\mathrm{Cu}$ (a), Ti (b), MS bronze powders (top figures) and samples after dot by dot electric-pulse sintering of this powders (bottom figures). 
ными поликристаллическими агрегатами. На Рис. 5а (вверху) приведена дифрактограмма исходного порошка меди, которая представлена только линиями этой фазы, имеющей ГЦК структуру. Определенный из анализа уширения линий размер ОКР меди в порошке составил порядка 80 нм. После спекания (Рис. 5а внизу) ширина практически не изменилась, что говорит о малом термическом влиянии спекания на структурное состояние частиц порошка. Малый нагрев частиц порошка связан с высокой электропроводностью меди и малым сопротивлением в контактах частиц.

На Рис. 5b (вверху) изображена дифрактограмма исходного порошка титана. На дифрактограмме присутствуют линии фаз $\alpha$-Ti и $\mathrm{TiH}_{2}$. Размер ОКР $\alpha$-Ті в порошке - 70 нм, размеры ОКР $\mathrm{TiH}_{2}$ не определялись ввиду малой интенсивности линий этой фазы. После спекания в образце на основе титана (Рис. 5b внизу) происходит небольшое уширение рентгеновских линий, что вызвано уменьшением размера ОКР (43 нм). Данное обстоятельство может быть вызвано перекристаллизацией исходной структуры порошка за счет высокой температуры нагрева. Действительно, о сильном нагреве порошка свидетельствует появление линий $\beta$-Ti, который, согласно диаграмме состояний, может образоваться только при температурах выше $882^{\circ} \mathrm{C}$. Титан имеет значительно более низкую электропроводность по сравнению с медью, кроме того, на его поверхности легко образуются слабо проводящие окисные слои, все это приводит к значительному увеличению электросопротивления порошкового слоя и более интенсивному нагреву спекаемого материала.

На Рис. 5с (вверху) представлена дифрактограмма порошка МС бронзы, на которой видны сильно уширенные линии ГЦК - твердого раствора олова в меди $\mathrm{Cu}(\mathrm{Sn})\left(\alpha\right.$-фаза) и следы линий интерметаллида $\mathrm{Cu}_{17} \mathrm{Sn}_{3}$ ( $\beta$-фаза). Размер ОКР $\alpha$-фазы - 5 нм. Из Рис. 5 с (внизу) видно, что после спекания в образце из бронзы произошли заметные изменения фазового состава по сравнению с исходным порошком. Дифракционные линии $\alpha$-фазы на основе меди стали заметно уже вследствие роста ОКР (13 нм). Одновременно происходит заметное увеличение содержания $\beta$-фазы. Эта фаза обладает широкой областью гомогенности и существует в диапазоне температур выше $590^{\circ} \mathrm{C}$. Очевидно образование $\beta$-фазы связано с нагревом частиц порошка, вызванным подплавлением локальных участков в зонах контакта частиц с последующим быстрым охлаждением за счет высокой теплопроводности остального объема. Бронза характеризуется достаточно высокой электропроводностью, которая, однако, существенно уступает электропроводности чистой меди. Поэтому разогрев бронзового порошка при спекании существенно выше по сравнению с медным. Определенную роль в формировании контактного сопротивления между частицами порошка имеет форма частиц. У медного порошка частицы дендритные, а у порошка меди - камневидные. Тепловыделение за счет превращения фаз и рекристаллизации при пропускании электрического тока через порошок может служить дополнительным источником его нагрева и приводить к более качественному свариванию частиц порошка.

\section{4. Заключение}

В работе опробована методика последовательного поточечного спекания металлических порошков импульсным электрическим током. Особенностью предложенной методики является использование источника переменного электрического тока малой мощности и недорогого оборудования. К особенностям способа также можно отнести меньшую производительность и точность изготовления изделий по сравнению с лазерными/электронно-лучевыми способами 3D печати. Показано, что с использованием данного метода возможно получение из электропроводящих порошков объемных материалов различной формы. При спекании порошков не происходит коробления получаемых образцов. Спекание происходит в результате подплавления частиц порошка, вызванного разогревом в зоне их электрического контакта. Поэтому на результаты спекания большое влияние оказывают температура плавления материала и контактное сопротивление между частицами. В наибольшей степени на пористость спеченных образцов влияет морфология порошков. Дисперсные порошки компактной формы способствуют получению более плотных образцов.

Благодарности/Acknowledgements. Работа выполнена при поддержке Российского фонда фундаментальных исследований и Фонда поддержки научно-проектной деятельности студентов, аспирантов и молодых ученых «Национальное интеллектуальное развитие» в рамках проекта № 17-33-80031 «мол_эв_а» и в рамках НИР рег. № АААА-А17-117022250038-7 государственного задания ФАНО Poccuu/This work was supported by the Russian Foundation for Basic Research and the Foundation for the Support of Scientific and Project Activities of Students, Postgraduates and Young Scientists "National Intellectual Development Project № 17-33-80031 «mol_ev_a» and by the Government of the Russian Federation (Federal Agency for Scientific Organizations) № AAAA-A17117022250038-7.

\section{Литература/References}

1. S. Bremen, W. Meiners, A. Diatlov. Laser Technik Journal. 9(2), 33 (2012).

2. K. Zhang, W. Liu, X. Shang. Optics \& Laser Technology. 39(3), 549 (2007).

3. L.E. Murr, S.M. Gaytan, D.A. Ramirez, E. Martinez, J. Hernandez, K. N. Amato, P. W. Shindo, F. R. Medina, R. B. Wicker. Journal of Materials Science \& Technology. 28(1), 1 (2012).

4. L. Thijs, F. Verhaeghe, T. Craeghs. Acta Materialia. 58(9), 3303 (2010).

5. K. Puebla, L.E. Murr, S. M. Gaytan. Mater. Science and App. 3, 259 (2012).

6. T. Nakamoto, N. Shirakawa, Y. Miyata, H. Inui. J. Mater. Process. Technol. 209, 5653 (2009).

7. A. Simchi, H. Pohl. Materials Science and Engineering A. 359, 119 (2003).

8. R. Morgan, A. Papworth, C. Sutcliffe. J. of Mater. Science. 
7, 3093 (2002).

9. H. Asgharzadeh, A. Simchi. Mater. Science and Eng. A. 403, 290 (2005).

10. W. Di, Y. Yongqiang, S. Xubin, C. Yonghua. Int. J. Adv. Manuf. Technol. 58, 1189 (2012).

11. H. K. Rafi, T.L. Starr, B.E. Stucker. Int. J. Adv. Manuf. Tech. 69, 1299 (2013).

12. E.G. Grigoriev, A.V. Rosliakov. Journal of materials processing technology. 191, 182 (2007).

13. A.G. Anisimov, V.I. Mali. Combustion, explosion and shock waves. 46, 237 (2010).

14. S. Kar, E. S. Sarma, V. B. Somu, N. K. Kishore, V. Srinivas. Indian journal of engineering and materials. 15, 343 (2008).

15. W. H. Lee, C. Y. Hyun. Applied surface science. 53, 4649 (2007).

16. W.H. Lee, J.W. Park, D.A. Puleo, J.Kim. Journal of materials science. 35, 593 (2000).

17. M. Alitavoli, A. Darvizeh. J. of Mater. Process. Tech. 209, 3542 (2009).

18. M.P. Malkov. Handbook of the physical and technical basics of cryogenics. Moscow, Energoatomizdat (1985) 436 p. (in Russian) [М. П. Малкова. Справочник по физико-техническим основам криогеники. Москва, Энергоатомиздат (1985) 436 с.]

19. V.E. Mikryukov. Thermal conductivity and electrical conductivity of metals and alloys. Gos. Scientific and technical publishing house for ferrous and non-ferrous metallurgy (1955) 260 p. (in Russian) [В.Е. Микрюков. Теплопроводность и электропроводность металлов и сплавов. Гос. Научно-тех. изд-во по черной и цветной металлургии (1955) 260 c.]

20. J. P. Kruth, P. Mercelis, J. Vaerenbergh. Rapid Prototyping J. 11, 36 (2005).

21. C. Rock, J. Qiu, K. Okazaki. J. of Mater. Science. 33, 241 (1998).

22. B. An, N.H. Oh, Y.W. Chun, Y.H. Kim, D.K. Kim, J. S. Park. Materials letters. 59, 2178 (2004).

23. B. E. Warren. X-ray diffraction. New-York, Dover Publ., Inc. (1990) $251 \mathrm{p}$.

24. R. K. Nandi, H. K. Kuo,W.H. Schlosberg. J. Appl. Cryst. 17, 22 (1984). 